\title{
Task 1.16 - Enhanced Mobility of Dense Nonaqueous-Phase Liquids (DNAPLs) Using Dissolved Humic Acids
}

\author{
Semi-Annual Report \\ July 1 - December 31, 1997 \\ By: \\ Marc D. Kurz \\ Edwin S. Olson \\ RECEIVEC \\ NOV 191998 \\ OSTI
}

Work Performed Under Contract No.: DE-FC21-93MC30097

For

U.S. Department of Energy

Office of Fossil Energy

Federal Energy Technology Center

P.O. Box 880

Morgantown, West Virginia 26507-0880

By

Energy \& Environmental Research Center

University of North Dakota

P. O. Box 9018

Grand Forks, North Dakota 58202-9018 


\section{DISCLAIMER}

This report was prepared as an account of work sponsored by an agency of the United States Government. Neither the United States Government, nor any agency thereof, nor any of their employees makes any warranty, express or implied, or assumes any legal liability or responsibility for the accuracy, completeness, or usefulness of any information, apparatus, product, or process disclosed or represents that its use would not infringe privately owned rights. Reference herein to any specific commercial product, process, or service by trade name, trademark, manufacturer, or otherwise does not necessarily constitute or imply its endorsement, recommendation, or favoring by the United States Government or any agency thereof. The views and opinions of authors expressed herein do not necessarily state or reflect those of the United States Government or any agency thereof.

Available to the public from the National Technical Information Service, U.S. Department of Commerce, 5285 Port Royal Road, Springfield, VA 22161; phone orders accepted at (703) $487-4650$.

\section{ACKNOWLEDGMENT}

This report was prepared with the support of the U.S. Department of Energy (DOE) Federal Energy Technology Center Cooperative Agreement No. DE-FC21-93MC30097. However, any opinions, findings, conclusions, or recommendations expressed herein are those of the author(s) and do not necessarily reflect the views of DOE.

\section{EERC DISCLAIMER}

LEGAL NOTICE This research report was prepared by the Energy \& Environmental Research Center (EERC), an agency of the University of North Dakota, as an account of work sponsored by U.S. Department of Energy. Because of the research nature of the work performed, neither the EERC nor any of its employees makes any warranty, express or implied, or assumes any legal liability or responsibility for the accuracy, completeness, or usefulness of any information, apparatus, product, or process disclosed, or represents that its use would not infringe privately owned rights. Reference herein to any specific commercial product, process, or service by trade name, trademark, manufacturer, or otherwise does not necessarily constitute or imply its endorsement or recommendation by the EERC. 


\section{DISCLAIMER}

Portions of this document may be illegible in electronic image products. Images are produced from the best available original document. 


\section{TABLE OF CONTENTS}

LIST OF FIGURES $\ldots \ldots \ldots \ldots \ldots \ldots \ldots \ldots \ldots \ldots \ldots \ldots \ldots \ldots \ldots \ldots \ldots \ldots \ldots$

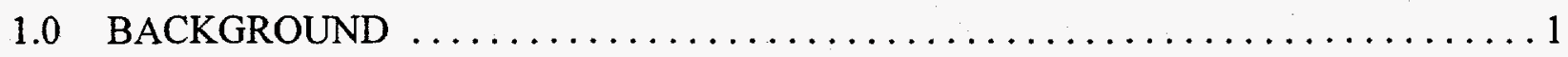

2.0 OBJECTIVES $\ldots \ldots \ldots \ldots \ldots \ldots \ldots \ldots \ldots \ldots \ldots \ldots \ldots \ldots \ldots \ldots \ldots \ldots \ldots$

3.0 STATEMENT OF WORK $\ldots \ldots \ldots \ldots \ldots \ldots \ldots \ldots \ldots \ldots \ldots \ldots \ldots \ldots \ldots \ldots$

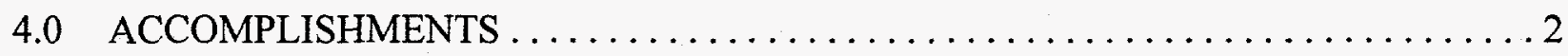

5.0 CONCLUSIONS AND FUTURE PLANS $\ldots \ldots \ldots \ldots \ldots \ldots \ldots \ldots \ldots \ldots \ldots$

\section{LIST OF FIGURES}

1 Leonardite-derived humic acid effects on TCE $\ldots \ldots \ldots \ldots \ldots \ldots \ldots \ldots \ldots$ 


\section{TASK 1.16 - ENHANCED MOBILITY OF DENSE NONAQUEOUS-PHASE LIQUIDS (DNAPLs) USING DISSOLVED HUMIC ACIDS}

\subsection{BACKGROUND}

Chlorinated solvent contamination is widespread across the U.S. Department of Energy (DOE) complex and other industrial facilities. Because of the physical properties of dense nonaqueous-phase liquids (DNAPLs), current treatment technologies are generally incapable of completely removing contamination from the source area. Incomplete removal means that the residual DNAPL will persist as a long-term source of groundwater contamination. When DNALPs occur in the subsurface, they resist remediation, owing to low water solubility, high viscosity and interfacial tension, and microbial recalcitrance. Because of their high density and polarity, they are usually found sorbed to aquifer solids or in pools on impermeable materials. Surfactants have been used with some success to reduce interfacial tension between the aqueous and organic phases and improve solubility of DNAPLs. However, surfactants are expensive and toxic and exhibit an oxygen demand. An alternative is the use of dissolved humic acids in improving DNAPL mobilization and solubilization. Humic acids, a natural form of organic carbon, are abundant, inexpensive, and nontoxic; biodegrade slowly (low oxygen demand); and have excellent mobilization properties. The present work is to establish the feasibility of using humates for enhancing DNAPL remediation.

\subsection{OBJECTIVES}

The specific objectives of this subtask are as follows:

- Evaluate the suitability of using humic acids to enhance the solubility and mobility of DNAPL contaminants sorbed to soils.

- Evaluate the toxicity and bioavailablity of the DNAPLs to biodegrading microorganisms.

\subsection{STATEMENT OF WORK}

To meet the first objective, we are evaluating a set of humic acids (two) with different chemical compositions and polarities for the following:

- Ability of the humates to mobilize/solubilize selected (three) DNAPLs

- Effect of key aquatic chemical parameters ( $\mathrm{pH}$, ionic strength, and calcium) on mobilization/solubilization

- Mobilization/solubilization in batch soil-water experiments (one soil)

- Removal rate via biotreatment with a well-established active microbial culture 


\subsection{ACCOMPLISHMENTS}

An analytical method was selected for the experiments under this subtask, and a calibration curve was constructed. This calibration curve is used to determine unknown contaminant concentrations in water being tested. The leonardite humic acid is derived by blending the oxidized coal with a $10 \%$ sodium hydroxide solution until the mixture is entirely liquified. The solution is then allowed to settle, and the excess solid (approximately $1 \%$ by weight) is discarded. The yield is approximately a $9.0 \mathrm{wt} \%$ concentration of humic acids, which is then diluted to the needed concentrations, ranging from $0.1 \%$ to $3 \%$.

Several batch experiments were completed using leonardite humic acid and trichloroethylene (TCE) solution in distilled water. Data were analyzed for the effect of the selected humic acid on the solubility of the TCE. Figure 1 is an illustration of leonardite-derived humic acid and its solubility effect on TCE. The linear relationship exhibited by the solubility data does not appear to demonstrate a micelle effect in the concentration range and $\mathrm{pH}$ studied. It does make solubility predictions reliable, however. Further analysis of this system is needed. A peat-derived humic acid has also been developed using the same laboratory protocol as the leonardite-derived humic acid. The more hydrophobic peat humate might exhibit a different curve or at least a different slope. However, because of a high workload on the analytical equipment and a problem with the detection capabilities in the batch experiments, the testing has been delayed by approximately 4 months. A new analytical method is just now being initiated, which will allow the extended batch experiments using other selected humic acids and chlorinated solvents to be completed. Data generated are being used to design the water and soil batch experiments in the next phase of testing. Following completion of the water batch tests, soil interactions will be evaluated with soil/water batch tests using the same DNAPLs. Bioavailablity testing and tests to determine effects from water chemistry variations will be initiated in conjunction with these efforts.

\subsection{CONCLUSIONS AND FUTURE PLANS}

Humic acids have been shown to possess solubility- and mobilization-enhancing properties similar to those of artificial surfactants. These humic acids, because they are abundant and inexpensive, may prove to be an attractive alternative to using artificial surfactants to enhance pump-and-treat of various DNAPL compounds in the subsurface. Tests on varying humic acids and DNAPLs are continuing and will contribute to the development of a database of information on the effectiveness of each humate on a variety of chlorinated solvents. 


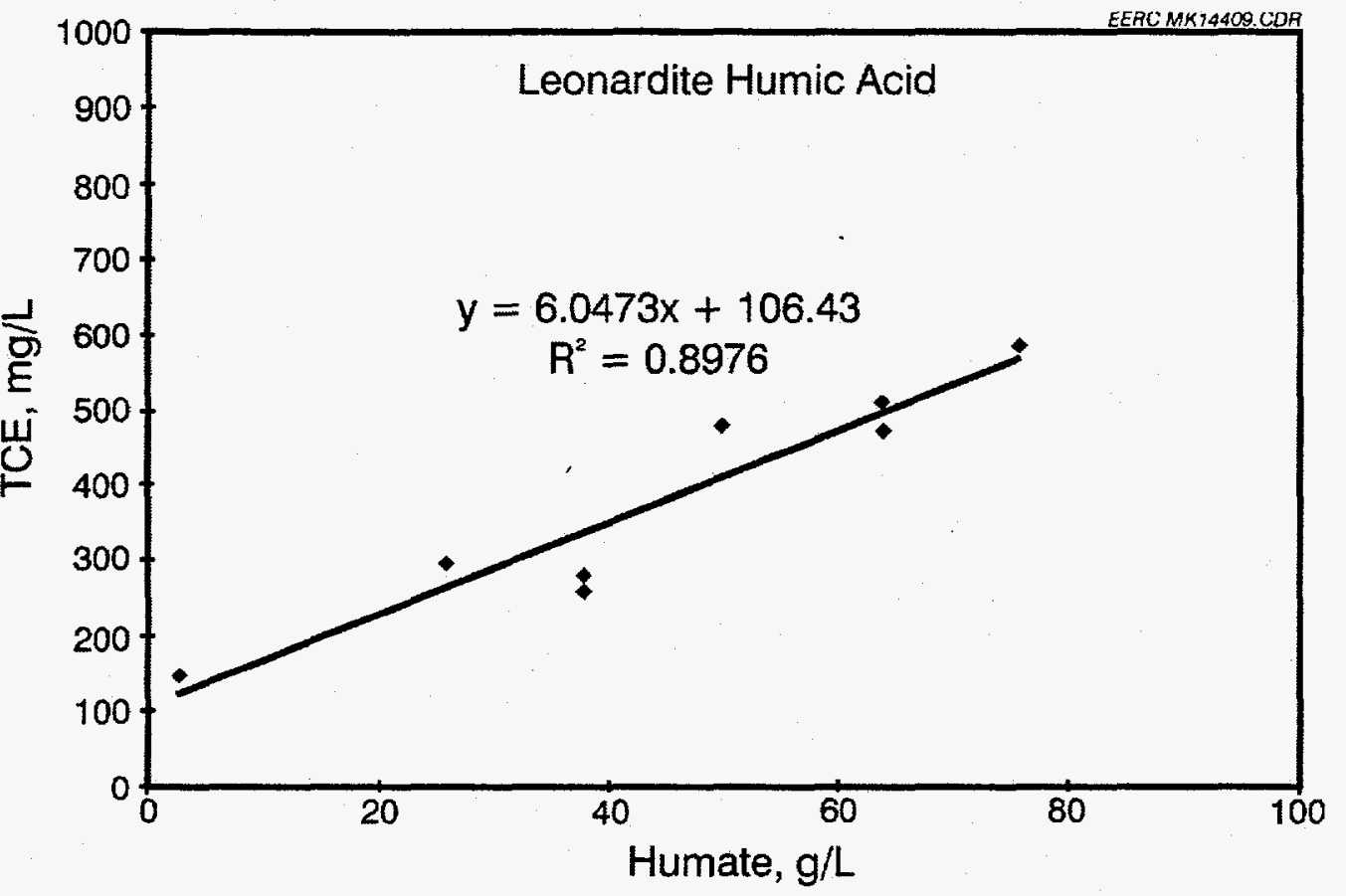

Figure 1. Leonardite-derived humic acid effects on TCE. 